\title{
Lung Adenoid Cystic Carcinoma
}

National Cancer Institute

\section{Source}

National Cancer Institute. Lung Adenoid Cystic Carcinoma. NCI Thesaurus. Code C5666.

A rare usually indolent lung carcinoma characterized by a cribiform and tubular pattern and the presence of glandular epithelial cells. Clinical symptoms include shortness of breath, cough, wheeze, hemopytsis and chest pain. 